\title{
PENERAPAN METODE RATIONAL UNIFIED PROCESS PADA KNOWLOEDGE MANAGEMENT SYSTEM UNTUK MENDUKUNG PROSES PEMBELAJARAN SEKOLAH MENEGAH ATAS
}

\author{
Muryan Awaludin ${ }^{1}$, Rinta Ridyustia Raveena ${ }^{2}$ \\ Program Studi Sistem Informasi \\ Universitas Dirgantara Marsekal Suryadarma \\ 1 muryanawaludin1@ gmail.com, ${ }^{2}$ rintaraveena @ gmail.com
}

\begin{abstract}
Utilization of information technology in schools is necessary to improve the quality of schools and also facilitate every learning, especially teaching and learning activities that occur in high school. Given the large class capacity and limited study space, knowledge management is needed to improve the quality of performance and competence of each individual, both students and teachers. The application of the Rational Unified Process (RUP) method on the Knowloedge Management System to support the high school learning process. Based on the results of tests carried out where the population sample is 963 students in the Bekasi area, the results of respondents show strongly agree $75.6 \%$, it can be concluded that the application of RUP to this knowledge management system can help teachers in the learning process by distributing material, especially in the form of videos. for students to better understand the material that has been presented.

Keywords: Knowledge Management, RUP, and Learning
\end{abstract}

\section{Pendahuluan}

Perkembangan dunia teknologi saat ini sudah sangat berkembang dengan pesat seiring berjalannya waktu, manusia banyak membuat terobosan baru dan mengembangkan ilmu baru untuk memperluas pengetahuan di bidang teknologi (Nainggolan, 2015). Salah satunya adalah adanya sistem berupa aplikasi berbasis web. Perkembangan serta pemanfaatan teknologi informasi saat ini juga sejalan dengan berkembangnya ilmu pengetahuan, tidak terkecuali pada bidang Pendidikan (Sudiarjo \& Kusdaryono, 2019). Pendidikan dalam penyelenggaraannya di sekolah melibatkan guru sebagai tenaga pendidik dan siswa/i sekolah sebagai peserta didik serta adanya interaksi belajar mengajar atau suatu proses pembelajaran (Kirom, 2017) (Tarigan, 2017). Di dalam pembelajaran, siswa/i di wajibkan untuk memahami materi pelajaran yang di ajarkannya dan di berikan oleh para tenaga pendidik serta memahami berbagai model pembelajaran agar dapat merangsang kemampuan siswa/i untuk belajar (Mutia, 2017). Sebagai tenaga pengajar sekaligus pendidik, para guru haruslah berusaha sekuat tenaga untuk dapat membuat para anak didiknya mengerti pembelajaran apa yang telah dia sampaikan, sekaligus dapat meningkatkan kompetensi, kualitas serta kualifikasi keprofesiannya (Suprapto \& Assegaff, 2018). Tentu dengan adanya ketersediaan sarana dan prasarana sekolah yang menjadi peran penting dalam mendukung terlaksananya proses Pendidikan.

Terlebih semenjak muncul dan menyebarnya pandemi Coronavirus Diseases 2019 (COVID19) di Indonesia, dampak virus COVID-19 ini terjadi di berbagai bidang seperti sosial, ekonomi, pariwisata dan juga bidang Pendidikan (Setiyani, Wahidin, Awaludin, \& Purwani, 2020). 
Salah satu yang juga terkena dampak karena COVID-19 ini adalah seluruh pelajar yang ada di Indonesia (Aji, 2020). Hal ini tentu menimbulkan berbagai macam permasalahan baik bagi para siswa/i maupun tenaga pendidik itu sendiri yang akan menghambat terlaksananya pembelajaran terlebih lagi selama metode pembelajaran daring (online) ini di jalankan (Aji, 2020) (Anshori, 2020).

Knowledge management system merupakan salah satu wadah untuk mempermudah dan mempercepat proses pembuatan, penyimpanan, pendistribusian keahlian pengalaman dan kolaborasi terkait materi ajar (Abdullah, Abdillah, \& Wijaya, 2019) (Laudon \& Laudon, 2014). Knowledge management memainkan peran penting karena menyediakan mekanisme koordinasi yang mendukung konversi sumber daya menjadi kemampuan, hal ini penting untuk kelangsungan hidup jangka panjang di dalam instansi karena memfasilitasi pengembangan kapabilitas lain dari instansi tersebut (Anderson, Bay, \& Mansingh, 2016). Kemampuan manusia dalam mengembangkan berbagai ilmu pengetahuan (knowledge) semakin baik dengan adanya knowledge secara tacit dan explicit (Awaludin, 2015). Dari pengembangan tersebut maka pengetahuan secara tacit dan explicit dapat digabungkan dan divariasikan hingga menjadi Knowledge Management System (Haryono, 2018). Knowledge Management System telah berhasil dikembangkan dan terbukti dapat membantu dan mempermudah pengolahan data dokumentasi (Shmueli, Bruce, Yahav, Patel, \& Lichtendahl, 2018). Salah satu pemecahannya adalah dengan merancang website Knowledge Management untuk para guru sebagai sarana sharing sumber belajar (Sugiarti \& Sulaeman, 2015). Adanya Knowledge Management membuat terjadinya penurunan jumlah komplain dari user serta penyelesaian permasalahan dapat ditangani dan diselesaikan dengan waktu yang cepat dan knowledge yang dimiliki dapat bertambah sehingga hal tersebut menjadi pengetahuan supaya permasalahan (komplain) dapat diselesaikan dengan cepat (Tarigan, 2017).

Strategi pembelajaran melalui video juga menjadi salah satu sumber belajar campuran meningkatkan pemahaman siswa, membantu pengembangan keterampilan, serta pengetahuan siswa (Coyne, Frommolt, Rands, Kain, \& Mitchell, 2018). Penyampaian media pejelasan atau pembelajaran yang menyertakan video seseorang yang berbicara dengan disertai penjelasan menunjukkan tingkat pengaruh yang lebih tinggi dan lebih menguntungkan daripada hanya dengan penjelasan atau pembelajaran dengan slide dan tangkapan layar saja (Gaston \& O'Neill, 2004) (Rublee, Rabaud, Konolige, \& Bradski, 2011). Model pembelajaran dengan berbasis video ini, menjadi model pembelajaran yang cukup berpengaruh, sehingga terdapat perbedaan hasil belajar yang lebih baik dari pelajar yang mendapatkan materi dengan menggunakan metode sharing video di banding membagikan sebuah materi tanpa penjelasan didalamnya (Afriansyah, 2019). Dengan menggunakan metode Software Development Life Cycle (SDLC) dan pemodelan Rational Unified Process (RUP) yang mana proses pengembangan perangkat lunak iterative sehingga dapat meningkatkan kualitas perangkat lunak yang dihasilkan (Malabay, 2016) (Tia \& K, 2018). Metode RUP dapat menangani risiko yang berhubungan dengan pengembangan kebutuhan sistem berdasarkan perubahan yang diinginkan oleh klien. Untuk mengurangi risiko tersebut dilakukan dengan pengujian pada setiap akhir tahapan RUP, sehingga akan mudah melakukan perubahan sebelum 
mencapai tahap akhir (System, Centre, \& Anjarwani, 2020). Hasil yang ditunjukkan setelah dilakukan pengujian disetiap tahapan RUP menunjukkan tidak terdapat masalah pada komponen maupun fungsional sistem pada lingkungan browser yang diuji, oleh karena itu dapat dipastikan sistem ini dapat berjalan pada berbagai lingkungan browser yang digunakan pengguna (Tamami, Mursityo, \& Pradana, 2019). Hasil yang ditunjukkan setelah pengujian, metode RUP dalam proses pengembangan sistem mudah untuk diimplementasikan karena menggunakan pendekatan yang dapat membantu tugas dan tanggung jawab organisasi (Ambika \& Supriya, 2018). Peneliti ingin membuat sebuah knowledge management system, yang akan memudahkan bagi para tenaga pendidik apabila mendapatkan sebuah media untuk menyalurkan berbagai sistem pembelajaran berupa materi-materi ajar kepada para pendidik agar para siswa/i dapat lebih memahami pada waktu yang sesuai sehingga proses pembelajaran dapat berlanjut (Olaniyi, 2020).

Selama sekolah online ini juga, para guru lebih banyak memberikan tugas kepada para muridnya, namun seperti yang kita tau dipelajaran non eksakta para murid mungkin akan cukup memahami ketika hanya di beri penjelasan singkat atau di berikan materi berupa sebuah dokumen berisi materi ajar yang di kirimkan oleh guru mata pelajaran tersebut, namun berbeda dengan mata pelajaran eksakta, para murid akan membutuhkan penjelasan materi yang lebih mendalam dan lebih terperinci lagi untuk memahami pelajaran tersebut. Selama sekolah secara online mereka memang mendapatkan penjelasan materi pelajaran eksakta tersebut melalui panggilan grup via zoom, namun yang menjadi kendala apabila ada murid yang bangun terlambat, berhalangan untuk masuk sekolah online, juga bila ada murid yang saat itu tidak memiliki kuota, kesulitan mendapatkan jaringan untuk melakukan proses belajar mengajar pada hari itu, ataupun para murid yang kurang dapat menangkap materi yang dijelaskan, menjadi tertinggal dalam pelajaran dan tidak bisa mengikuti materi yang dijelaskan oleh guru tersebut hari itu. Hal itu akan berimbas pada murid yang akhirnya tidak bisa memahami materi ajar yang di sampaikan oleh guru dan juga berimbas pada nilai akademis mereka selama sekolah online berlangsung.

Keterangan yang diatas berdasarkan data yang telah di dapatkan penulis setelah melakukan wawancara pada salah staf SMAN di Bekasi serta menyebarkan angket kuesioner kepada 303 responden yang merupakan siswa/i SMAN Bekasi. Hasil dari kuesioner tersebut menyatakan bahwa $56,2 \%$ responden menyatakan biaya untuk pembelajaran online mahal. 98\% responden setuju bahwa tidak semua siswa memiliki akses internet yang lancar. $66 \%$ responden tidak setuju bahwa tidak ada kendala selama menjalankan sekolah online. $76,3 \%$ responden tidak setuju bahwa siswa lebih tertarik dalam melakukan pembelajaran daring (online) dibandingkan tatap muka (offline). $78,6 \%$ responden setuju bahwa kurangnya kedisiplinan antara siswa dan guru terhadap sekolah online. 79,2\% responden setuju bahwa kehadiran siswa pada sekolah online terkadang hanya jadi formalitas. $92,1 \%$ responden setuju bahwa Siswa mengalami kesulitan dalam mengerjakan tugas yang diberikan guru 92,4\% responden setuju bahwa siswa mengalami kesulitan dalam memahami pelajaran khususnya pelajaran Eksak (Matematika, Biologi, Fisika, Kimia). $53,8 \%$ responden setuju bahwa siswa sering terlambat mengikuti kelas online (daring). Kemudian 92,7\% responden setuju bahwa siswa menjadi terbantu 
apabila sekolah menyediakan platform berupa website berisi materi video penjelasan dari guru mata pelajaran terkait.

Pemanfaatan teknologi informasi di sekolah sangatlah diperlukan untuk meningkatkan kualitas sekolah dan juga memudahkan setiap pembelajaran, khususnya aktifitas belajar mengajar yang terjadi pada SMAN di Bekasi, mengingat kapasitas kelasnya yang cukup banyak dan ruang belajar yang cukup terbatas. Knowledge management (Manajemen Pengetahuan) sangat dibutuhkan untuk meningkatkan kualitas kinerja serta kompetensi setiap individu baik para murid ataupun para guru.

\section{Penelitian Terkait}

\subsection{Deny Iskandar dan Hady Syahrial (2019)}

Pada penelitian yang dilakukan oleh (Iskandar, Syahrial, Buana, \& Luhur, 2019) masalah yang dihadapi mengenai informasi, pengetahuan, aturan atau prosedur pengembangan karir dosen terkadang tidak sampai pada dosen serta tidak merata penyebarannya dan hanya dimiliki oleh staf bagian kepangkatan akademik dosen. Solusi yang diterapkan menggunakan metode pendekatan Deskriptif Kualitatif, penelitian ini juga menggunakan metode pengembangan sistem yaitu metode Rational Unified Process (RUP), analisis dan perancangan sistem dengan pendekatan berorientasi obyek menggunakan Unified Modeling Language (UML), pengujian validasi menggunakan metode User Acceptance Testing (UAT). Dari hasil penilaian dapat diambil kesimpulan bahwa responden pengguna sistem telah memilih Setuju (S) sebesar 74,05\% dan sistem sudah mulai di aplikasikan dan disosialisakan kepada seluruh karyawan.

\subsection{Lilik Joko Susant dan Hendra Kurniawan (2018) \\ Penelitian (Susanto \& Kurniawan,} 2018) dilakukan dengan permasalah penyampaian informasi masih belum optimal serta belum terdapatnya media untuk menampung informasi serta tempat atau wadah untuk berbagi pengetahuan mengenai teknik hidroponik. Solusi yang lakukan dengan membuatkan sistem Knowledge Management komunitas hidroponik ini dirancang dengan menggunakan metode RUP (Rational Unified Process). Penelitian yang dihasilkan berupa berbasis outcome dengan menfaat pada sumber daya manusia yaitu pengurus dan masyarakat bisa mengakses informasi dengan cepat dan akurat. Dapat diakses melalui perangkat personal computer dan juga perangkat smartphone yang tersambung ke jaringan internet.

\subsection{Ariq Cahya Wardhana, Yani Nurhadryani, Sri Wahjuni (2020) Maslah yang diangkat pada} penelitian (Wardhana et al., 2020) adalah meningkatnya jumlah populasi masyarakat membuat KMS perlu dikembangkan agar masyarakat menangkap, menyimpan, mencari, dan membagi pengetahuan Budidaya Hidroponik. Solusi yang dilakukan dengan menggunakan metode Knowledge Management Life Cycle melalui identifikasi pengetahuan tacit maupun explicit dari komunitas hidroponik. Implementasi sistem menggunakan aplikasi berbasis Web dengan pendekatan objectoriented yang sudah diuji oleh pakar. Hasil uji coba menunjukkan bahwa fungsi standar klasifikasi KMS sudah terpenuhi dan berfungsi dengan baik. KMS ini sudah berhasil dirancang dan dikembangkan menggunakan pendekatan knowledge management sytem life cycle. 


\section{Landasan Teori \\ 3.1 Perancangan Sistem}

Perancangan sistem dapat diartikan perencanaan dari pembuatan suatu sistem yang menyangkut berbagai komponen sehingga akan menghasilkan sistem yang sesuai dengan hasil dari tahap analisa sistem (Riyanto, 2017). Perancangan sistem informasi juga merupakan langkah pertama dalam fase pengembangan rekayasa produk atau sistem. Perancangan itu adalah proses penerapan berbagai teknik dan prinsip yang bertujuan untuk mendefinisikan sebuah peralatan, satu proses atau satu sistem secara detail yang membolehkan dilakukan realisasi fisik (Nadeak et al., 2016).

Sistem merupakan kumpulan dari elemen-elemen atau komponen-komponen yang merupakan definisi lebih luas dan lebih banyak diterima, dimana komponen tersebut tidak dapat berdiri sendiri, semuanya saling berinteraksi dan saling membentuk satu kesatuan sehingga sasaran sistem dapat tercapai (Sutopo, Cahyadi, \& Arifin, 2016). Sistem dibuat untuk menangani sesuatu yang terjadi berulang kali atau yang sering terjadi. Suatu sistem dapat dirumuskan sebagai kumpulan atau variabel-variabel yang terorganisasi, saling berinteraksi, saling tergantung satu sama lain dan terpadu. Informasi merupakan data di dalam satu kontektual tertentu yang merupakan kumpulan data dan terkait dengan penjelasan, interpretasi dan berhubungan dengan materi lainnya mengenai objek, peristiwa-peristiwa atau proses tertentu (Nainggolan, 2015).

Sistem Informasi adalah seperangkat komponen yang saling berhubungan yang berfungsi mengumpulkan, memproses, menyimpan, dan mendistribusikan informasi untuk mendukung pembuatan keputusan dan pengawasan dalam organisasi (Sugiarti \& Sulaeman, 2015)
(Tamami et al., 2019). Dapat disimpulkan oleh penelliti bahwa Sistem Informasi adalah suatu komponen sistem yang saling berhubungan untuk mengatur suatu jaringan komunikasi pada suatu organisasi.

Internet merupakan salah satu produk dari perkembangan teknologi informasi yang telah sangat membantu dalam memudahkan pekerjaan sehari-hari seperti pencarian informasi, pertukaran data dan informasi. Organisasi ataupun perorangan telah memakai internet untuk menunjang pertukaran data, informasi, dan pencarian pengetahuan sehingga knowledge yang mereka miliki akan berkembang (Abdullah et al., 2019).

Untuk Indonesia, pengguna internet menurut data yang di terbitkan melalui http://www.internetworldstats.com/top20.h tm telah masuk ke peringkat 4 besar dunia sebanyak lebih dari 171 ratus juta pengguna internet.

Tabel 1 Data Pengguna Internet

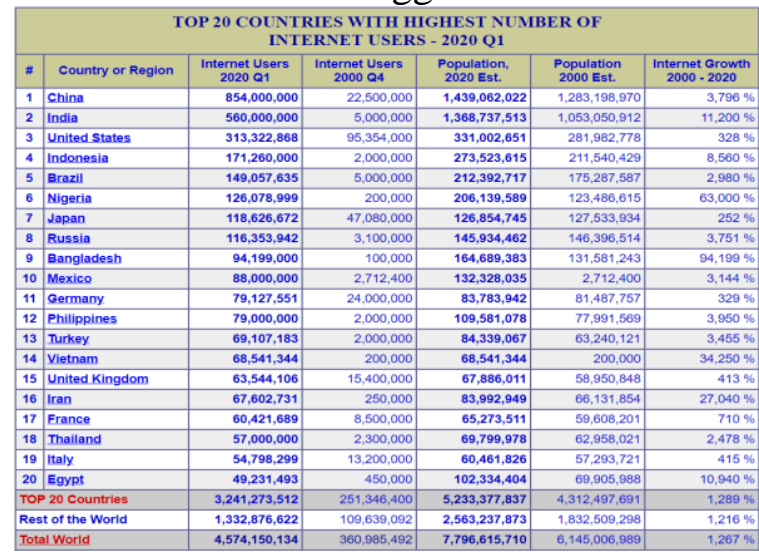

Pengertian Pembelajaran adalah sebuah kegiatan guru mengajar atau membimbing siswa menuju proses pendewasaan diri, tenaga kependidikan yang berkualifikasi sebagai guru, dosen, konselor, tutor, instruktur, fasilitator, dan sebutan yang sesuai dengan kekhususannya, serta berpartisipasi dalam menyelenggaran Pendidikan (Nadeak et al., 2016) (Kirom, 2017) (Rinaldi, Daryati, 
\& Arthur, 2017). Usaha tersebut dapat dilakukan oleh seseorang atau sekelompok orang yang memiliki kemampuan atau kompetensi dalam merancang dan atau mengembangkan sumber belajar yang diperlukan (Furi, 2017) (Agustien, Umamah, \& Sumarno, 2018) (Agustien et al., 2018) (Apriansyah, 2020).

\subsection{Knowledge Management}

Knowledge atau Pengetahuan merupakan hasil dari rangkaian bagaimana kita memproses data mentah menjadi informasi yang berdasarkan fakta, kebenaran, kepercayaan, penilaian, pengalaman, dan keahlian si pengguna menjadi informasi yang berguna, mempunyai arti yang berbeda dengan data maupun informasi tetapi saling berhubungan antara data informasi dan knowledge namun Knowledge berada di level yang lebih tinggi dari data dan informasi (Nainggolan, 2015).

Knowledge merupakan aset atau sumber yang mempunyai peranan penting baik bagi individu maupun organisasi, sehingga penggunaan internet saat ini tidak hanya mengacu pada pencarian informasi, namun juga pada kebutuhan untuk pencarian pengetahuan (Haryono, 2018) (Abdullah et al., 2019).

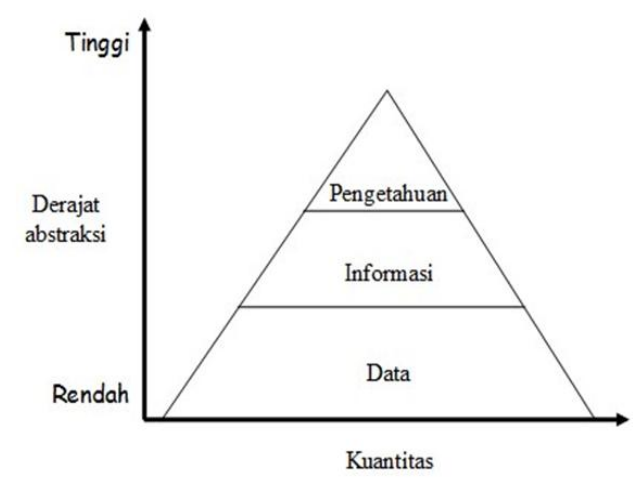

Gambar 1 Abstraksi Data, Informasi, dan Pengetahuan
Pengetahuan dapat dibagi dalam dua jenis, yaitu:

1. Tacit Knowledge (Pengetahuan Implisit)

Tacit knowledge adalah pengetahuan yang dimiliki oleh seseorang terdapat pada pakar baik individu maupun masyarakat. Tacit knowledge bersifat sangat personal dan sulit dirumuskan. Pengetahuan ini berupa perasaan pribadi, intuisi, bahasa tubuh, pengaman fisik serta petunjuk praktis (Rule of Thumb). Sehingga Tacit knowledge berupa pengalaman dari pakar individu dan melibatkan faktor-faktor seperti keyakinan, perspektif dan nilai-nilai pribadi yang disampaikan ke orang lain (Sonatha, Rahmayuni, Alanda, \& Saputra, 2018) (Haryono, 2018).

2. Explicit Knowledge (Pengetahuan Ekplisit)

Explicit knowledge adalah pengetahuan yang dapat diekspresikan dalam bentuk kata, angka, bagan, atau dalam berbagai bentuk dokumentasi seperti prosedur, operasi standar, paper, laporan penelitian, buku, artikel, manuskrip, paten, dan software serta disampaikan dalam bentuk ilmiah, spesifikasi, manual dan sebagainya. Knowledge jenis ini dapat segera diteruskan dari satu individu ke individu lainnya secara formal dan sistematis. (Sonatha et al., 2018) (Haryono, 2018).

Manajemen juga menganalisa, menetapkan tujuan/sasaran serta mendeterminasi tugas-tugas dan kewajiban-kewajiban secara baik, pemanfaatan sumber daya yang dimiliki organisasi melalui kerjasama para anggota 
untuk mencapai tujuan organisasi secara efektif dan efesien (Wijaya, 2016).

Siklus Knowledge Management merupakan penggambaran proses yang dilalui oleh manajemen pengetahuan. Dibawah ini ada tahapan-tahapan siklus knowledge management (Nainggolan, 2015) (Kaawoan et al., 2017).

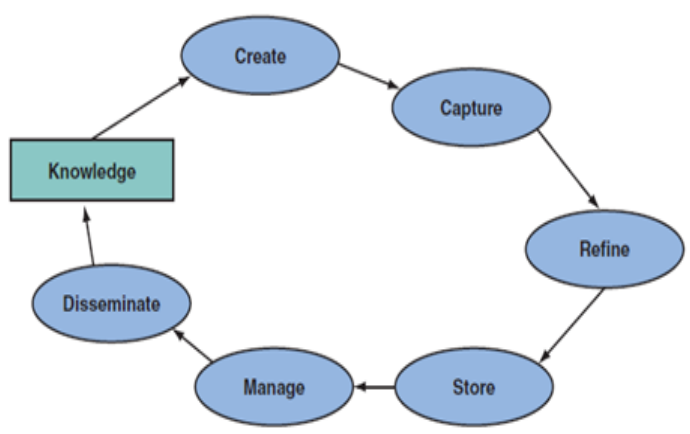

Gambar 2 Siklus Knowledge Management

Dibawah ini adalah proses inti dari knowledge management (Raudeliūnienè, Davidavičienè, \& Jakubavičius, 2018) (Darudiato \& Setiawan, 2013).

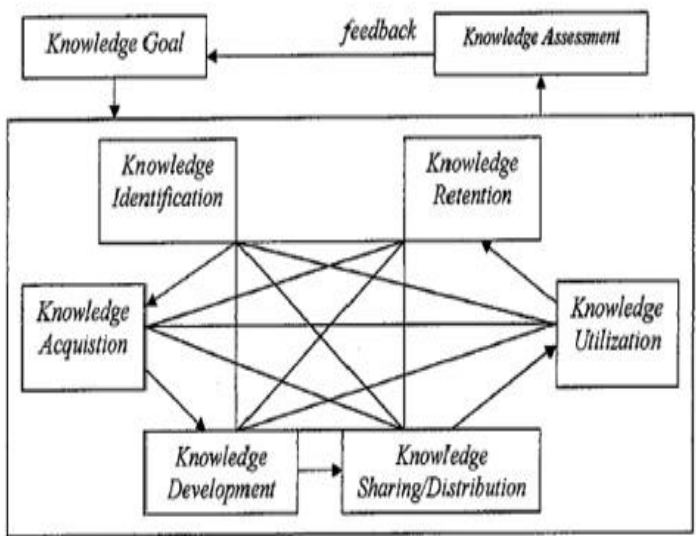

Gambar 3 Proses Inti Knowledge Management

Rational Unified Process (RUP) merupakan proses pengembangan perangkat lunak menggunakan pendekatan usecase-driven yang berarti mengacu pada usecase pada saat penentuan kebutuhan perangkat lunak, dan iterative yang berarti pengembangan berulang dan incremental sehingga dapat meningkatkan kualitas perangkat lunak yang dihasilkan. RUP digunakan untuk mengembangkan perangkat lunak berbasis komponen dan berfokus pada UML (Tia \& K, 2018).

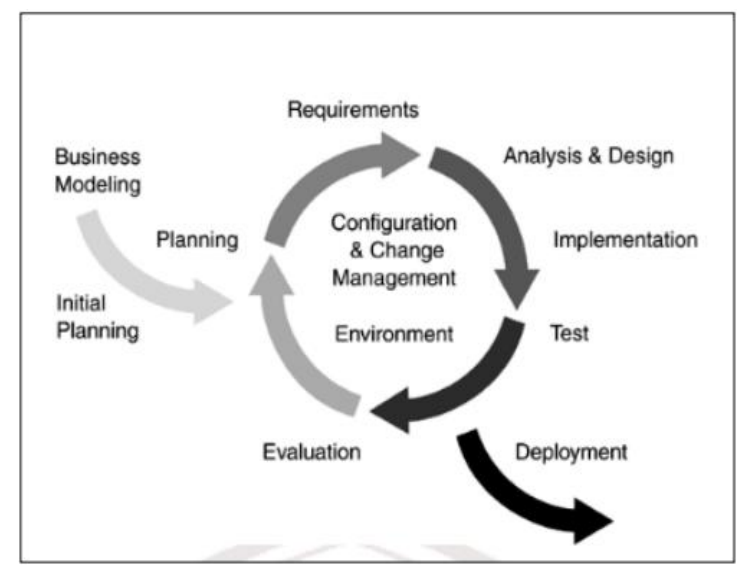

Gambar 4 Proses Iteratif RUP

RUP memiliki empat tahapan yaitu inception, elaboration, contruction, dan transition. Berikut ini adalah penjelasan mengenai empat tahapan dalam pengembangan RUP (Awaludin, 2019).

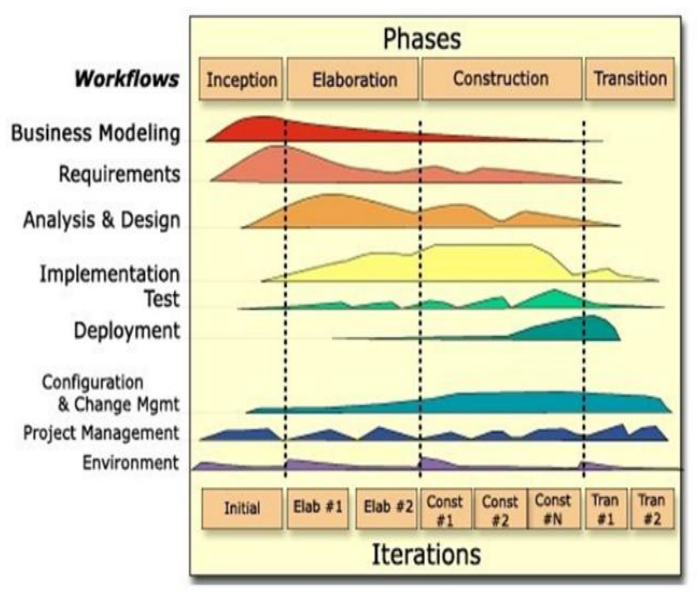

Gambar 5 Arsitektur Model RUP 


\section{Implementasi dan Pembahasan}

\subsection{Metode Rational Unified Process}

Menentukan konteks dan sample pengguna dengan total siswa di SMAN Bekasi mendapatkan jumlah 963, dan peneliti mengambil populasi 963 siswa.

$$
\begin{aligned}
n & =\frac{N}{1+N e^{2}} \\
n & =\frac{963}{1+963\left(0,05^{2}\right)} \\
n & =\frac{963}{1+963(0.0025)} \\
n & =\frac{963}{1+2,4075} \\
n & =\frac{963}{3,4075} \\
n & =282,611 \\
\underline{n=283} & \text { (Pembulatan) }
\end{aligned}
$$

Setelah menghitung jumlah reponen dengan Rumus Slovin, dapat diketahui bahwa pengambilan sampel yaitu 283 orang.

Untuk menentukan kebutuhan pengguna, penulis membuatkan kuesioner yang disebarkan melalui form online. Kuesioner disebarkan kepada 963 siswa/I SMAN Bekasi dengan 2 jurusan dalam 1 angkatan (Nama, NIS, NISN, Jurusan terlampir pada Lampiran 1). Kuesioner terdiri dari 21 pertanyaan dengan menggunakan pengukuran Teknik Skala Likert. Setelah itu tahap selanjutnya adalah analisis yang dapat dilakukan sebagai berikut: a. Menentukan Interpretasi Skor Perhitungan

Jumlah skor tertinggi dengan jawaban "Sangat Setuju" adalah 4 dan jumlah responden 283, maka 4 × $283=1132$, Sedangkan untuk skor terendah dengan jawaban "Sangat Tidak Setuju" adalah 1 dan jumlah responden 283, maka 1 × $283=283$. Jadi, jika didapatkan hasil skor penilaian responden adalah hasil nilai yang didapatkan dengan menggunakan rumus index \% Rumus Index $\%=$ Total Skor $/ \mathrm{X}$ x 100.

b. Menentukan Interpretasi Skor berdasarkan Interval

Rumus Interval I = 100 / Jumlah Skor (Likert)

Maka 100/4 = 25 Hasil $(\mathrm{I})=25$, Ini adalah interval jarak terendah $0 \%$ hingga tertinggi $100 \%$, tabel 4.1 berikut menjelaskan kriteria interpretasi skor tanggapan responden berdasarkan interval:

Tabel 2 Kriteria Interpretasi Skor Tanggapan Responden

\begin{tabular}{|l|l|}
\hline Intervasi Korelasi & Jawaban \\
\hline $0 \%-24 \%$ & Sangat Tidak Setuju \\
\hline $25 \%-49 \%$ & Tidak Setuju \\
\hline $50 \%-74 \%$ & Setuju \\
\hline $75 \%-100 \%$ & Sangat Setuju \\
\hline
\end{tabular}

Adapun pertanyaan dan hasil kuesioner yang telah dibagikan kepada 283 responden sebagai berikut: 


\begin{tabular}{|c|c|c|}
\hline No & Pertanyaaan & Hasil \\
\hline 1 & Pembelajaran daring bisa dilakukan kapan saja dan dimana saja & $75,3 \%$ (Setuju) \\
\hline 2 & $\begin{array}{l}\text { Siswa lebih tertarik dalam melakukan pembelajaran daring (online) } \\
\text { dibandingkan tatap muka (offline). }\end{array}$ & $55,5 \%$ (Setuju) \\
\hline 3 & Biaya untuk pembelajaran daring (online) lebih murah. & $62,9 \%$ (Setuju) \\
\hline 4 & Tidak semua siswa memiliki akses internet yang lancar. & 95,1\% (Sangat Setuju) \\
\hline 5 & Sekolah online yang dilakukan saat ini berjalan dengan lancar. & $74 \%$ (Setuju) \\
\hline 6 & $\begin{array}{l}\text { Materi yang disampaikan oleh guru saat sekolah online tersampaikan } \\
\text { dengan baik (khususnya mata pelajaran Eksak). }\end{array}$ & $69 \%$ (Setuju) \\
\hline 7 & $\begin{array}{l}\text { Siswa memahami materi yang dijelaskan oleh guru dengan baik } \\
\text { (khususnya mata pelajaran Eksak). }\end{array}$ & $67 \%$ (Setuju) \\
\hline 8 & Guru lebih sering memberikan tugas daripada materi pembelajaran. & $85 \%$ (Sangat Setuju) \\
\hline 9 & $\begin{array}{l}\text { Sekolah Online berjalan sesuai dengan jadwal yang telah ditetapkan } \\
\text { sebelumnya. }\end{array}$ & $81 \%$ (Sangat Setuju) \\
\hline 10 & Tidak ada kendala selama menjalankan sekolah online. & $60 \%$ (Setuju) \\
\hline 11 & Kurangnya kedisiplinan antara siswa dan guru terhadap sekolah online. & 77\% (Sangat Setuju) \\
\hline 12 & Kehadiran siswa pada sekolah online terkadang hanya jadi formalitas & 79\% (Sangat Setuju) \\
\hline 13 & $\begin{array}{l}\text { Siswa mengalami kesulitan dalam mengerjakan tugas yang diberikan } \\
\text { guru. }\end{array}$ & $89 \%$ (Sangat Setuju) \\
\hline 14 & $\begin{array}{l}\text { Siswa mengalami kesulitan dalam memahami pelajaran khususnya } \\
\text { pelajaran Eksak (Matematika, Biologi, Fisika, Kimia). }\end{array}$ & 92\% (Sangat Setuju) \\
\hline 15 & Siswa sering terlambat mengikuti kelas online (daring). & 69\% (Setuju) \\
\hline 16 & $\begin{array}{l}\text { Keadaan rumah tidak mendukung siswa dalam melakukan } \\
\text { pembelajaran daring. }\end{array}$ & $68 \%$ (Setuju) \\
\hline 17 & $\begin{array}{l}\text { Siswa menjadi terbantu apabila sekolah menyediakan platform berupa } \\
\text { website berisi materi video penjelasan dari guru mata pelajaran terkait. }\end{array}$ & $87 \%$ (Sangat Setuju) \\
\hline
\end{tabular}

\section{Kesimpulan}

Berdasarkan hasil pengujian yang dilakukan dimana hasil responden sangat setuju $75,6 \%$, maka dapat disimpulkan bahwa adanya knowledge management system ini dapat membantu guru dalam proses pembelajaran dengan cara membagikan materi khususnya berupa video untuk siswa-siswa agar dapat lebih memahami materi yang telah disampaikan. Guru yang membagikan materi khususnya materi berupa video kedalam website ini membuat siswa akan lebih mudah memahami materi yang diberikan khususnya dengan pelajaran eksakta. 


\section{REFERENCES}

Abdullah, Y. S., Abdillah, L. A., \& Wijaya, A. (2019). Bina Darma Conference on Computer Science Rancang Bangun Knowledge Management System Pengelolaan Materi Ajar Bahasa Inggris Berbasis Web pada SMPN 1 Indralaya. 465-472.

Afriansyah. (2019). PENGEMBANGAN MODEL PEMBELAJARAN VIRTUAL (MPV) BERBASIS VIDEO E-LEARNING MOODLE. 8.

Agustien, R., Umamah, N., \& Sumarno, S. (2018). Pengembangan Media Pembelajaran Video Animasi Dua Dimensi Situs Pekauman di Bondowoso Dengan Model Addie Mata Pelajaran Sejarah Kelas X IPS. Jurnal Edukasi, 5(1), 19. https://doi.org/10.19184/jukasi.v5i1.8010

Aji. (2020). Dampak Covid-19 pada Pendidikan di Indonesia: 7(5), 395-402. https://doi.org/10.15408/sjsbs.v7i5.15314

Ambika, N. K., \& Supriya, P. (2018). Detection of vanilla species by employing image processing approach. Procedia Computer Science, 143, 474-480. https://doi.org/10.1016/j.procs.2018.10.420

Anderson, R., Bay, M., \& Mansingh, G. (2016). Towards a Comprehensive Process Model for Transitioning MIS to KMS. 12(1), 1-17. https://doi.org/10.4018/IJKM.2016010101

Anshori. (2020). DAMPAK COVID-19 TERHADAP PROSES PEMBELAJARAN DI Mts AlASYHAR BUNGAH GRESIK. https://doi.org/10.30868/im.v3i02.803

Apriansyah. (2020). PENGEMBANGAN MEDIA PEMBELAJARAN VIDEO BERBASIS ANIMASI MATA KULIAH ILMU BAHAN BANGUNAN DI PROGRAM STUDI PENDIDIKAN TEKNIK BANGUNAN FAKULTAS TEKNIK UNIVERSITAS NEGERI JAKARTA. 9(1).

Awaludin, M. (2015). Penerapan Metode Distance Transform Pada Linear Discriminant Analysis Untuk Kemunculan Kulit Pada Deteksi Kulit. Journal of Intelligent Systems, 1(1), 49-55.

Awaludin, M. (2019). Penerapan Radio Frequency Identification Pada Sistem Informasi Perpustakaan Sebagai Alat Bantu Mahasiswa Universitas Xyz. Jurnal Sistem Informasi Universitas Suryadarma, 6(2), 203-212. https://doi.org/10.35968/jsi.v6i2.326

Coyne, E., Frommolt, V., Rands, H., Kain, V., \& Mitchell, M. (2018). Simulation videos presented in a blended learning platform to improve Australian nursing students' knowledge of family assessment. \#pagerange\#. https://doi.org/10.1016/j.nedt.2018.04.012

Darudiato, S., \& Setiawan, K. (2013). Knowledge Management: Konsep dan Metodologi. Jurnal ULTIMA InfoSys, 4(1), 11-17. https://doi.org/10.31937/si.v4i1.237

Furi, U. L. (2017). PENGEMBANGAN MEDIA VIDEO MATA PELAJARAN KOMPOSISI FOTO DIGITAL BAGI SISWA KELAS XI MULTIMEDIA. 91-100.

Gani, A. G. (2016). e-Learning Sebagai Peran Teknologi Informasi Dalam Modernisasi Pendidikan. Jurnal Sistem Informasi Universitas Suryadarma, 3 (1), https://doi.org/10.35968/jsi.v3i1.52

Gaston, K. J., \& O’Neill, M. A. (2004). Automated species identification: Why not? Philosophical Transactions of the Royal Society B: Biological Sciences, 359(1444), 655-667. https://doi.org/10.1098/rstb.2003.1442 
Haryono, W. (2018). ANALISIS KNOWLEDGE MANAGEMENT SYSTEM PADA APLIKASI SIA( SISTEM INFORMASI AKADEMIK ) UNIVERSITAS PAMULANG Evaluate Existing Infrastructure Form The KM Team Knowledge Capture Implement the KM system. 646-651.

Iskandar, D., Syahrial, H., Buana, U. M., \& Luhur, U. B. (2019). Knowledge Management System Pengembangan Karir Dosen Menggunakan SECI Model: Studi Kasus Pada Universitas Mercu Buana. 1-7.

Kaawoan, Y. Y. I., Sentinuwo, S., Sambul, A., Informatika, T., Sam, U., Manado, R., ... Bahu, U. (2017). PENGETAHUAN UNTUK MENDUKUNG PROSES UNIVERSITAS SAM RATULANGI. 12(1).

Kirom. (2017). PERAN GURU DAN PESERTA DIDIK DALAM PROSES PEMBELAJARAN BERBASIS MULTIKULTURAL. 3, 69-80.

Laudon, K. C., \& Laudon, J. P. (2014). Management Information Systems THIRTEENTH EDITION GLOBAL EDITION.

Malabay. (2016). Pemanfaatan Flowchart Untuk Kebutuhan Deskripsi Proses Bisnis. Jurnal Ilmu Komputer, 12, 21-26.

Mutia, I. (2017). Perancangan Knowledge Management System ( KMS ) Kurikulum 2013 Menggunakan Model Tiwana dan Zack. 3(2), 152-162.

Nadeak, B., Parulian, A., Siregar, S. R., Pendahuluan, I., Perancangan, A., Pembelajaran, B., \& Learning, B. (2016). PERANCANGAN APLIKASI PEMBELAJARAN INTERNET DENGAN. $3(4), 54-57$.

Nainggolan, E. R. (2015). MEMBANGUN KNOWLEDGE MANAGEMENT SYSTEM UNTUK MEMBENTUK KNOWLEDGE SHARING MENGGUNAKAN METODE KM-ROADMAP. $X I(1), 60-69$.

Olaniyi, N. E. E. (2020). Threshold concepts : designing a format for the flipped classroom as an active learning technique for crossing the threshold. 3.

Raudeliūnienė, J., Davidavičienė, V., \& Jakubavičius, A. (2018). Knowledge management process model. Entrepreneurship and Sustainability Issues, 5(3), 542-554. https://doi.org/10.9770/jesi.2018.5.3(10)

Rinaldi, A. A., Daryati, D., \& Arthur, R. (2017). Penggunaan Media Pembelajaran Berbasis Audio Visual untuk Mata Pelajaran Konstruksi Bangunan. Jurnal PenSil, 6(1), 1-7. https://doi.org/10.21009/jpensil.v6i1.7231

Riyanto. (2017). PERANCANGAN APLIKASI SISTEM INFORMASI GEOGRAFIS (SIG) LOKASI MINIMARKET DI KOTA JAMBI BERBASIS ANDROID. 9(2), 295-304.

Rublee, E., Rabaud, V., Konolige, K., \& Bradski, G. (2011). ORB: An efficient alternative to SIFT or SURF. Proceedings of the IEEE International Conference on Computer Vision, 2564-2571. https://doi.org/10.1109/ICCV.2011.6126544

Setiyani, L., Wahidin, M., Awaludin, D., \& Purwani, S. (2020). Analisis Prediksi Kelulusan Mahasiswa Tepat Waktu Menggunakan Metode Data Mining Naïve Bayes: Systematic Review. Faktor Exacta, 13(1), 38-47. https://doi.org/10.30998/faktorexacta.v13i1.5548 
Shmueli, G., Bruce, P. C., Yahav, I., Patel, N. R., \& Lichtendahl, K. C. (2018). DATA MINING FOR BUSINESS ANALYTICS (Concepts, Techniques, and Applications in R). In John Wiley \& Sons, Inc. (Vol. 4).

Sonatha, Y., Rahmayuni, I., Alanda, A., \& Saputra, I. (2018). Rancang Bangun Aplikasi Knowledge Management Berbasis Web. 18(2), 133-140.

Sudiarjo, A., \& Kusdaryono, A. (2019). Perototipe Knowledge Management System Untuk Mendukung Proses Pembelajaran Dengan Pendekatan Seci Dan Desain Mvc. 01, 7-14.

Sugiarti, Y., \& Sulaeman, O. (2015). RANCANG BANGUN KNOWLEDGE MANAGEMENT SYSTEM BAHAN AJAR ONLINE DALAM MENINGKATKAN KOMPETENSI GURU MTS NEGERI 2 PAMULANG. 1-6.

Suprapto, C. A., \& Assegaff, S. (2018). ANALISIS DAN PERANCANGAN KNOWLEDGE MANAGEMENT SYSTEM PADA SMA NEGERI 6 KOTA JAMBI. 3(1), 973-988.

Susanto, L. J., \& Kurniawan, H. (2018). Penerapan Knowledge Mangement System dalam Manajemen Data Kegiatan Hidroponik ( Studi Kasus: Komunitas Hidroponik Bandar Lampung ). 1(1).

Sutopo, P., Cahyadi, D., \& Arifin, Z. (2016). SISTEM INFORMASI EKSEKUTIF SEBARAN PENJUALAN KENDARAAN BERMOTOR RODA 2 DI KALIMANTAN TIMUR BERBASIS WEB. 11(1).

System, C., Centre, M., \& Anjarwani, S. E. (2020). PENERAPAN METODE RATIONAL UNIFIED PROCESS ( RUP ) DALAM PENGEMBANGAN SISTEM INFORMASI MEDICAL CHECK UP PADA CITRA MEDICAL CENTRE ( The Application of RationalUnifiedProcess ( RUP ) in Development of a Medical. 2(1), 76-88.

Tamami, J. H., Mursityo, Y. T., \& Pradana, F. (2019). Pengembangan Sistem Informasi Penjualan Awesam Merchandise Dengan Metode Rational Unified Process. 3(5).

Tarigan. (2017). PENGARUH PENERAPAN KNOWLEDGE MANAGEMENT SYSTEM TERHADAP EFEKTIVITAS KINERJA KARYAWAN. 1-6.

Tia, T. K., \& K, W. A. (2018). MODEL SIMULASI PENGEMBANGAN PERANGKAT LUNAK MENGGUNAKAN RATIONAL UNIFIED PROCESS ( RUP ). 2, 33-40.

Wardhana, A. C., Nurhadryani, Y., Wahjuni, S., Komputer, D. I., Informatika, F., \& Korespondensi, P. (2020). KNOWLEDGE MANAGEMENT SYSTEM BERBASIS WEB TENTANG BUDIDAYA WEB-BASED KNOWLEDGE MANAGEMENT SYSTEM CONCERNING HYDROPONIC CULTIVATION TO SUPPORT SMART SOCIETY. 7(3). https://doi.org/10.25126/jtiik.202072200

Wijaya. (2016). DASAR-DASAR MANAJEMEN. 